\title{
Condom-use errors and problems among teens attending clinics: better or worse than young adults?
}

This article was published in the following Dove Press journal:

Open Access Journal of Contraception

2 March 2012

Number of times this article has been viewed

\author{
Richard Crosby ${ }^{1-3}$ \\ Richard J Charnigo' \\ Lydia A Shrier ${ }^{4}$ \\ 'College of Public Health, University \\ of Kentucky, Lexington, KY, USA; \\ ${ }^{2}$ Rural Center for AIDS/STD \\ Prevention, Indiana University, \\ Bloomington, IN, USA; ${ }^{3}$ The Kinsey \\ Institute for Research in Sex, Gender, \\ and Reproduction, Bloomington, IN, \\ USA; ${ }^{4}$ Children's Hospital Boston, \\ Boston, MA, USA
}

Objectives: To compare the frequency of condom-use errors and problems between teens (15-19 years of age) and young adults (20-24 years of age) attending clinics. Also, to assess whether the odds of experiencing condom failure were influenced by age group, gender, and motives for condom use.

Methods: As part of a larger study of condom effectiveness, youth (15-24 years of age) from five clinics, in three US cities, were recruited $(\mathrm{N}=263)$. Data were prospectively collected using daily electronic diaries. For each episode of condom use with penile-vaginal sex, youths were asked to respond to questions assessing seven errors and five problems in condom use. Data analyses entailed statistical modeling with generalized estimating equations.

Results: Teens did not significantly differ from their older counterparts on any of the seven condom-use errors or any of the five condom-use problems. Of all condom-use events, teens reported that $20 \%$ did not involve condom use from start-to-finish of sex, $14.7 \%$ involved a condom that had dried out, $8.1 \%$ involved rushed application, $6.7 \%$ did not involve adequate lubrication, and other errors and problems occurred less often. Further, condom failure was not predicted by age group, gender, or motive for using condoms. Significant interaction effects were not observed.

Conclusions: Several forms of condom-use errors/problems occurred with similar frequency when comparing teens and young adults, suggesting a need to intervene to improve condomuse behavior regardless of age.

Keywords: condoms, teens, sexually transmitted diseases, sexual behavior

\section{Introduction}

In the United States (US), the epidemics of chlamydia and gonorrhea are most likely to affect young people, especially those in their teens. ${ }^{1,2}$ Moreover, unintended pregnancy rates among US teens continue to be far higher in contrast to those in other developed nations. ${ }^{3}$ One frontline prevention strategy for these related epidemics has involved the promotion of condom use to teens. Evidence supports the efficacy of condoms for both reduction of sexually transmitted disease (STD) incidence and unintended pregnancy. ${ }^{4-7}$ Unfortunately, condom promotion efforts for teens may lack the necessary emphasis on the correct use of condoms, leaving open the possibility that teens may experience errors and problems with their use.

One important question regarding teens and condom use is whether the quality of their use improves as they age into young adulthood. Despite an expanding body of empirical literature on condom-use errors and problems, ${ }^{8-24}$ published studies have neglected to address the question of association between age and quality of condom use.
Correspondence: Richard Crosby University of Kentucky College of Public Health, I2I Washington Ave,

Lexington, KY 40506-0003, USA

$\mathrm{Tel}+\mathrm{l} 8592575678$

Fax + I 8593232933

Email crosby@uky.edu
Open Access Journal of Contraception 2012:3 17-22

(C) 2012 Crosby et al, publisher and licensee Dove Medical Press Ltd. This is an Open Access article

Dovepress

http://dx.doi.org//0.2147/OAJC.S26440 which permits unrestricted noncommercial use, provided the original work is properly cited. 
A particularly important population for this question is teens attending clinics that diagnose and treat STDs. Teens (15-19 years of age) and young adults (20-24 years of age) represent two-thirds of the estimated 19 million new cases of STDs that occur in the US each year. ${ }^{25}$ In addition to STD prevention, condoms are a stand-alone contraceptive option or, more importantly, condoms are one component of dualmethod use. Whether the objective is disease prevention or pregnancy prevention, it is quite clear from past research that user error rather than product error is the main factor in condom failure. ${ }^{6,8-10,12,17}$

Unfortunately, even basic descriptive studies of condomuse errors and problems among clinic-based populations of teens have not been published, thereby creating a dearth of evidence regarding this vital strategy of protecting sexual health. Understanding condom-use errors and problems is best achieved through analysis on individual condom-use events. ${ }^{15}$ Event-level data are important to the research question simply because observed associations are based on the same sexual event (rather than correlations within a block of time such as 6 months). ${ }^{15}$ Accordingly, the purpose of this study was to describe the frequency of condom-use errors and problems among teens (15-19 years old) attending clinics that diagnose and treat STDs and to compare the findings with those for young adults (20-24 years old). In addition, the study assessed whether the odds of experiencing condom failure (errors and problems directly leading to loss of protection) were influenced by: (1) age (teen versus young adult), (2) gender, (3) whether event-level condom use was motivated to avoid either the transmission or acquisition of STDs, or 4) whether event-level condom use was motivated to avert pregnancy.

\section{Methods}

\section{Study sample}

Data were collected from December 2007 through April 2011 as part of a larger study of condom effectiveness. Established patients were recruited from five sites: a publicly-funded STD clinic in the southern US, another in the mid-western US, and an STD clinic of a large general hospital and two adolescent medical clinics affiliated with a pediatric hospital, all in urban New England. Only the adolescent clinics enrolled persons under 18 years of age (for convenience, all participants are referred to as men and women). Eligibility criteria included speaking English; reporting penile-vaginal intercourse in the preceding 3 months; agreeing to be tested for chlamydia, gonorrhea, and trichomoniasis by providing a urine specimen; agreeing to provide contact information; and providing written informed consent (parental consent was waived for adolescents).

At the southern clinic, the mid-western clinic, and one New England clinic, staff referred patients who met all of the eligibility criteria to a research assistant to confirm eligibility, and to further explain the study. At the adolescent recruitment sites, the study was listed on a research recruitment flag (a sheet of paper showing that the patient is potentially eligible for study recruitment), which was attached to the appointment paperwork of age-eligible patients. The research flag included a brief description of the study and an area for providers to report patients' recruitment status. This information was used to keep a running list of potential participants, which was used by the research assistant to contact eligible patients. Across the three clinics not recruiting adolescents, 1424 patients agreed to be screened for eligibility. Of these, 1297 were eligible and were thus invited to participate, with 795 agreeing to do so yielding a participation rate of $61.3 \%$. Adding to these 795 were the patients recruited from the adolescent clinics $(n=133)$; the baseline sample size was 928. Of these 928 people, 263 were selected for analysis in the current study based on their age ( 24 years or younger) and their use of condoms, at least one time, during penile-vaginal sex reported in the observation period. The study protocol was approved by the institutional review boards at the Office of Research Integrity at the University of Kentucky (KT) and the Committee on Clinical Investigation of Children's Hospital Boston (Boston, MA).

\section{Measures}

The study was designed to collect event-level data using daily electronic diaries. A key advantage of daily assessment is that it is likely to greatly decrease recall bias or inaccurate reporting. ${ }^{26,27}$ Participants were instructed to complete daily sex-event diaries using the Configurable Electronic RealTime Assessment System (Personal Improvement Computer Systems, Inc, Reston, VA, USA) on a password-protected personal digital assistant. At a time of day specified by study participants, the personal digital assistant was programmed to signal them once each day for up to 180 days. The signal prompted them to file an event report, with the opening question asking if they had penile-vaginal sex in the past 24 hours. For those responding "yes" to this question, a second question asked whether a condom was used. For those indicating that a condom was used, event-specific condom-use errors and problems were then assessed. These questions were asked in a "yes versus no" format and they included seven errors (not using a new condom, condom 
contacting sharp objects, putting on the condom after starting to have sex or taking the condom off before finishing sex, allowing condom to dry out, not having adequate lubrication on the condom, using a damaged condom, and not allowing adequate time to put condom on the penis) and five problems (erection loss during condom use, breakage, slippage during sex, slippage during withdrawal, and leakage).

\section{Data analysis}

Because of the correlations inherent to multiple observations on the same participant (ie, the use of sex events as the observation units), generalized estimating equation models, utilizing an exchangeable correlation matrix, were employed for all analyses. Analyses were performed with SPSS (version 19.0; SPSS Inc, Chicago, IL). To begin, bivariate comparisons of condom-use errors and problems were made between those younger than 20 years and those aged 20-24 years at the time of study enrollment. Next, a binary "condom failure" outcome variable was created as a composite of four items, with failure defined by an affirmative response to at least one of the following: put condom on late or removed it early, condom broke, condom slipped off during sex, condom slipped off during withdrawal. Binary logistic regression was then performed to assess how condom failure related to age group (teen versus young adult), gender, and whether sex-event condom use was motivated by avoiding either the transmission/ acquisition of STDs or pregnancy.

\section{Results}

The mean age of the sample was 20.5 years (standard deviation = 2.37). Ninety-four percent identified as African American/Black and 67\% were female. Over the 6-month period of observation the retention rate was $67 \%$. During the data collection period, 3571 condom-use events were reported by the teens and young adults in this sample.

\section{Frequency of condom-use errors and problems}

Table 1 displays the bivariate comparisons between teens and their young adult counterparts for each of the seven condom-use errors. As shown, teens did not significantly differ from their older counterparts on any of the seven condom-use errors. The most common error was not using condoms from start-to-finish of penile-vaginal sex, reported for approximately one of every five condom-use events (20.0\% of all events for teens). Also, about $15 \%$ of the condom-use events were reported as involving a condom
Table I Bivariate comparisons of condom-use errors between teens and young adults

\begin{tabular}{|c|c|c|c|c|}
\hline $\begin{array}{l}\text { Condom-use } \\
\text { error }\end{array}$ & $\begin{array}{l}\text { Percentage } \\
\text { of total events }\end{array}$ & EOR & $95 \% \mathrm{Cl}$ & $P$ \\
\hline \multicolumn{5}{|c|}{ Did not use a new condom } \\
\hline Younger & 3.6 & 0.85 & $0.43-1.72$ & 0.66 \\
\hline Older & 3.0 & & & \\
\hline \multicolumn{5}{|c|}{ Allowed condom to contact sharp objects } \\
\hline Younger & 1.6 & 1.05 & $0.39-2.86$ & 0.92 \\
\hline Older & 3.7 & & & \\
\hline \multicolumn{5}{|c|}{ Put condom on late or removed it early } \\
\hline Younger & 20.0 & 1.04 & $0.72-1.48$ & 0.84 \\
\hline Older & 19.9 & & & \\
\hline \multicolumn{5}{|c|}{ Allowed condom to dry out } \\
\hline Younger & 14.7 & 1.34 & $0.84-2.14$ & 0.22 \\
\hline Older & 15.0 & & & \\
\hline \multicolumn{5}{|c|}{ Condom not adequately lubricated } \\
\hline Younger & 6.7 & 1.10 & $0.53-2.27$ & 0.81 \\
\hline Older & 10.5 & & & \\
\hline \multicolumn{5}{|c|}{ Used damaged condom } \\
\hline Younger & 2.0 & 0.99 & $0.53-1.84$ & 0.97 \\
\hline Older & 2.0 & & & \\
\hline \multicolumn{5}{|c|}{ Did not have adequate time to put condom on } \\
\hline Younger & 8.1 & 0.75 & $0.46-1.22$ & 0.25 \\
\hline Older & 7.5 & & & \\
\hline
\end{tabular}

Abbreviations: EOR, estimated odds ratio (based on generalized estimating equations); $\mathrm{Cl}$, confidence interval.

that had dried out ( $14.7 \%$ for teens). Although less common, approximately $7 \%-10 \%$ of all condom-use events involved the use of a condom that was not adequately lubricated $(6.7 \%$ for teens). Also, about $8 \%$ of condom-use events occurred under conditions reported by the study participant as lacking adequate time to apply condoms ( $8.1 \%$ for teens). Other errors occurred less often.

Table 2 displays the bivariate comparisons between teens and their young adult counterparts for each of the five condom-use problems. As shown, teens did not significantly differ from their older counterparts on any of the five assessed condom-use problems. The most frequently reported problem was erection loss during sex, occurring during about $13 \%$ of all condom-use events for teens and $10 \%$ for young adults. Just under $5 \%$ of the condom-use events involved reported slippage during withdrawal (4.6\% for teens), with slippage during sex occurring somewhat less often (3.7\% for teens). Breakage and leakage were not uncommon, occurring in about $3 \%-4 \%$ of all condom-use events $(3.6 \%$ and $3.0 \%$, respectively, for teens).

\section{Incidence and predictors of condom failure}

Of the 3571 condom-use events, 800 (22.4\%) involved one or more of the four assessed forms of condom failure. 
Table 2 Bivariate comparisons of condom-use problems between teens and young adults

\begin{tabular}{|c|c|c|c|c|}
\hline $\begin{array}{l}\text { Condom-use } \\
\text { problem }\end{array}$ & $\begin{array}{l}\text { Percentage of } \\
\text { total events }\end{array}$ & EOR & $95 \% \mathrm{Cl}$ & $P$ \\
\hline \multicolumn{5}{|c|}{ Erection was lost during condom use } \\
\hline Younger & 13.4 & 0.79 & $0.45-1.36$ & 0.39 \\
\hline Older & 10.0 & & & \\
\hline \multicolumn{5}{|l|}{ Condom broke } \\
\hline Younger & 3.6 & 0.80 & $0.45-1.42$ & 0.44 \\
\hline Older & 2.9 & & & \\
\hline \multicolumn{5}{|c|}{ Condom slipped off during sex } \\
\hline Younger & 3.7 & 0.83 & $0.44-1.55$ & 0.55 \\
\hline Older & 2.9 & & & \\
\hline \multicolumn{5}{|c|}{ Condom slipped off during withdrawal } \\
\hline Younger & 4.6 & 0.83 & $0.48-1.43$ & 0.50 \\
\hline Older & 4.0 & & & \\
\hline \multicolumn{5}{|l|}{ Condom leaked } \\
\hline Younger & 3.0 & 0.72 & $0.24-2.12$ & 0.55 \\
\hline Older & 3.8 & & & \\
\hline
\end{tabular}

Abbreviations: EOR, estimated odds ratio (based on generalized estimating equations); $\mathrm{Cl}$, confidence interval.

At a bivariate level, this frequency did not significantly differ between teens $(23.5 \%)$ and young adults $(22.1 \%)$ (estimated odds ratio [OR], 1.06; 95\% confidence interval [CI]: 0.76-1.48; $P=0.74$ ).

Table 3 displays the multivariate associations from the logistic regression model predicting condom failure. Of note, in this model $29.2 \%$ of the condom-use events were reported by teens, $67.6 \%$ of the events were reported by females, $59.0 \%$ were reported to occur when condoms were being used to avert transmission or acquisition of an STD, and $8.7 \%$ occurred when condoms were being used for pregnancy prevention. As shown, after adjusting for gender effects, the use of condoms to prevent STD transmission or acquisition, and the use of condoms for pregnancy protection, the difference between teens and their young adult counterparts remained nonsignificant. Though not presented in Table 3, age-group interaction effects were also explored; however, none were significant $(\times$ gender, $P=0.36 ; \times$ using condoms

Table 3 Comparison of event-specific condom failures between teens and young adults, controlling for gender and reasons for condom use

\begin{tabular}{lccc}
\hline & EOR & $\mathbf{9 5 \%} \mathbf{C l}$ & $\boldsymbol{P}$ \\
\hline Predictor & & & \\
Younger than 20 years & 1.20 & $0.78-1.85$ & 0.41 \\
Male sex & 0.93 & $0.46-1.85$ & 0.83 \\
Used condom to avoid & 0.72 & $0.44-1.17$ & 0.19 \\
STD transmission/acquisition & & & \\
Used condom to avoid pregnancy & 0.70 & $0.34-1.44$ & 0.33 \\
\hline
\end{tabular}

Abbreviations: EOR, estimated odds ratio (adjusted for all other variables in the model); $\mathrm{Cl}$, confidence interval. for STD prevention, $P=0.94 ; \times$ using condoms for pregnancy prevention, $P=0.90$ ).

Finally, in light of the null comparison between teens and young adults, the multivariate logistic regression model was refitted using age as a continuous predictor instead of the dichotomous predictor age group. Again, however, no significant age effects were observed (estimated OR, 1.04; 95\% CI: 0.98-1.11; $P=0.24)$.

\section{Discussion}

To the best of our knowledge, this is the first published study to comprehensively assess condom-use errors and problems experienced by teens using event-level data and to compare teens to young adults on the frequencies of such occurrences. Our methodology allowed for an implicit test of whether errors and problems may diminish as teens enter their early twenties. Such an implicit test may indeed be more rigorous than a traditional prospective cohort design simply because the social context is held relatively constant in a 6-month study as opposed, for example, to one lasting 6 years. Moreover, the fact that we were able to have teens and young adults maintain daily records of any condom-use behaviors added considerable rigor to the study by creating event-level data. Under these rigorous conditions, in this clinic-based sample, we observed that seven condom-use errors and five condom-use problems did not occur significantly less often among young adults than among teens. Though the caveat that null findings may constitute Type II testing errors is omnipresent, the consistent pattern of null findings across every comparison made in this study suggests that teens do not improve the quality of their condom use as they age into their early twenties. While disheartening, this conclusion is quite logical given a general lack of available education or counseling programs that teach teens the skills needed to avoid these errors and problems with condoms. In turn, the "typical-use failure rate" of condoms as a diseaseprevention or a pregnancy-prevention method increases as a consequence of uncorrected errors and problems carried into adulthood.

Given that 800 of the condom-use events (22.4\%) involved one or more forms of condom failure, it is imperative to note that our findings have implications for an improved education/counseling focus on the correct use of condoms in addition to the long-standing focus on consistent use. Moreover, the multivariate findings suggest that condom failure does not diminish between the teen years and the early twenties, and that errors or problems occur regardless of whether teens or young adults are female or male. 
Further, the multivariate findings suggest that condom failures are not associated with event-level motivations to use condoms (disease prevention or pregnancy prevention). Collectively, these findings suggest that the need for safer sex programs with a focus on correct use of condoms exists on a widespread basis for persons aged 15-24 years, regardless of sex or motive for condom use. Indeed, this observation suggests that a unitary "correct use" program could be implemented in clinics that diagnose and treat STDs for youth. Past research suggests that such programs may greatly reduce STD incidence. ${ }^{28-31}$

Two observations about the findings are also warranted. First, that $20 \%$ of all condom-use events among teens do not involve use from start-to-finish of sex is an important indication that teens need more explicit and directive instruction regarding the need to always have the condom on the penis during penetrative sex. Certainly, teens use condoms for a reason and thus the perceived risk of pregnancy or disease is not mitigated by this "partial use." Second, that about one of every seven condom-use events among teens involved erection loss is yet another indication of need to escalate condom-use education for teens. The concern in this regard is that erection loss associated with condom use may lead teens to abandon this contraceptive method.

\section{Limitations}

As is true for most sexuality research, findings are limited by the validity of self-report. The use of a convenience sample limits the generalizability of the findings to all US teens and young adults. However, this is not necessarily a limitation given the need to understand and intervene with those teens at greatest risk, eg, teens attending clinics as opposed to those recruited through community-based recruitment. Also, it should be noted that the sample was composed primarily of African American youth thereby precluding generalization to youth of other races. However, this is less of a limitation than a strength of the study given the urgent need to respond to disproportionate epidemics of STDs, including HIV, among young African Americans. Finally, the 33\% attrition rate may have created a sample bias - one that may have led to underestimation of error/problem frequencies if those experiencing more errors or problems had a greater tendency to cease keeping the daily electronic records.

\section{Conclusions}

Teens attending clinics may not improve the quality of their condom use, for penile-vaginal sex, as they enter young adulthood. Several forms of condom-use errors or problems occurred with comparable frequency among teens and young adults suggesting a need to intervene regardless of age (or sex). More than one of every five acts of condom use culminated in condom failure thereby greatly diminishing the prophylactic value of what may otherwise be a highly reliable method of protecting the sexual health of young people.

\section{Acknowledgments}

Support for this project was provided by a grant to the first author from the National Institutes of Allergies and Infectious Diseases (5 R01 AI068119).

\section{Disclosure}

The authors report no conflicts of interest in this work.

\section{References}

1. Centers for Disease Control and Prevention. Sexually Transmitted Diseases Surveillance, 2009. Atlanta, GA: centers for Disease Control and Prevention, US Dept of Health and Human Services; 2010.

2. Centers for Disease Control and Prevention. Establishing a Holistic Framework to Reduce Inequities in HIV, Viral Hepatitis, STDs, and Tuberculosis in the United States. Atlanta GA: Centers for Disease Control and Prevention, US Dept of Health and Human Services; 2010. Available from: http://www.cdc.gov/socialdeterminants.

3. Martin JA, Hamilton BE, Sutton PD, Ventura SJ, Matthews TJ, Osterman MJ. Births: Final data for 2008. Natl Vital Stat Rep. 2010; 59(1):1, 3-71.

4. Cates W Jr. Estimates of the incidence and prevalence of sexually transmitted diseases in the United States. Sex Transm Dis. 1999;26(Suppl 4):S2-S7.

5. Centers for Disease Control and Prevention. Condoms and STDs: Fact sheet for public health personnel. Available from: http://www.cdc.gov/ condomeffectiveness/latex.htm. Accessed June 29, 2011.

6. Crosby R, Bounse S. Condom effectiveness: Where we now? Sexual Health. In press 2012.

7. Holmes KK, Levine R, Weaver M. Effectiveness of condoms in preventing sexually transmitted infections. Bull World Health Organ. 2004;82(6):454-461.

8. Crosby R, Salazar LF, DiClemente RJ, Yarber WL, Caliendo AM, Staples-Horne M. Accounting for failures may improve precision: evidence supporting improved validity of self-reported condom use. Sex Transm Dis. 2005;32(8):513-515.

9. Warner L, Stone KM, Macaluso M, Buehler JW, Austin HD. Condom use and risk of gonorrhea and chlamydia: a systematic review of design and measurement factors assessed in epidemiologic studies. Sex Transm Dis. 2006;33(1):36-51.

10. Warner L, Macaluso M, Austin HD, et al. Application of the casecrossover design to reduce unmeasured confounding in studies of condom effectiveness. Am J Epidemiol. 2005;161(8):765-773.

11. Warner L, Newman DR, Austin HD, et al; Project RESPECT Study Group. Condom effectiveness for reducing transmission of gonorrhea and chlamydia: the importance of assessing partner infection status. Am J Epidemiol. 2004;159(3):242-251.

12. Crosby RA, DiClemente RJ, Wingood GM, Lang D, Harrington KF. Value of consistent condom use: a study of sexually transmitted disease prevention among African American adolescent females. Am J Public Health. 2003;93(6):901-902.

13. Crosby RA, Sanders SA, Yarber WL, Graham CA, Dodge B. Condom use errors and problems among college men. Sex Transm Dis. 2002;29(9):552-557. 
14. Crosby R, Sanders S, Yarber WL, Graham CA. Condom use errors and problems: a neglected aspect of studies assessing condom effectiveness. Am J Prev Med. 2003;24(4):367-370.

15. Crosby R, DiClemente RJ, Yarber WL, Snow G, Troutman A. An eventspecific analysis of condom breakage among African American men at risk of HIV acquisition. Sex Transm Dis. 2008;35(2):174-177.

16. Crosby R, Yarber WL, Sanders SA, Graham CA. Condom discomfort and associated problems with their use among university students. Am J Coll Health. 2005;54(3):143-147.

17. Crosby R, DiClemente RJ, Yarber WL, Snow G, Troutman A. Refining self-reported condom use among young men at risk of HIV acquisition. Sex Health. 2007;4(3):211-212.

18. Crosby RA, Salazar LF, Yarber WL, et al. A theory-based approach to understanding condom errors and problems reported by men attending an STI clinic. AIDS Behav. 2008;12(3):412-418.

19. Yarber WL, Crosby RA, Graham CA, et al. Correlates of putting condoms on after sex has begun and removing them before sex ends: a study of men attending an urban public STD clinic. Am J Mens Health. 2007;1(3):190-196.

20. Crosby RA, Noar S, Head S, Webb E. Condoms and other barrier methods of STI and HIV prevention. In: Gupta S, Kumar B, editors. Sexually Transmitted Infections. 2nd ed. New Delhi, India: Elsevier; 2011.

21. Sanders SA, Yarber WL, Kaufman E, Milhausen RA, Graham CA, Crosby RA. Condom use errors and problems: a global view. Sexual Health. 2012;9:81-95.

22. Civic D, Scholes D, Ichikawa L, et al. Ineffective use of condoms among young women in managed care. AIDS Care. 2002;14(6):779-788.

23. Richters J, Gerofi J, Donovan B. Why do condoms break or slip off in use? An exploratory study. Int J STD AIDS. 1995;6(1):11-18.

24. Spruyt A, Steiner MJ, Joanis C, et al. Identifying condom users at risk for breakage and slippage: findings from three international sites. $\mathrm{Am}$ J Public Health. 1998;88(2):239-244.
25. Weinstock H, Berman S, Cates W Jr. Sexually transmitted diseases among American youth: incidence and prevalence estimates, 2000. Perspect Sex Reprod Health. 2004;36(1):6-10.

26. Shiffman S. Real-time self-report of momentary states in the natural environment: computerized ecological momentary assessment. In: Stone AA, Turkkan JS, Bachrach CA, Jobe JB, Kurtzman HS, Cain VS, editors. The Science of Self-Report: Implications for Research and Practice. Mahwah, NJ: Lawrence Erlbaum Associates; 2000.

27. Larson R, Csikszentmihalyi M. The experience sampling method. In: Reis H, editor. Naturalistic Approaches to Studying Social Interaction; Vol 15. San Francisco, CA: Jossey-Bass; 1983.

28. Crosby R, DiClemente RJ, Charnigo R, Snow G, Troutman A. A brief, clinic-based, safer sex intervention for heterosexual African American men newly diagnosed with an STD: a randomized controlled trial. Am J Public Health. 2009;99 Suppl 1:S96-S103.

29. Jemmott LS, Jemmott JB III, O'Leary A. Effects on sexual risk behavior and STD rate of brief HIV/STD prevention interventions for African American women in primary care settings. Am J Public Health. 2007;97(6):1034-1040.

30. Kamb ML, Fishbein M, Douglas JM Jr, et al; for Project RESPECT Study Group. Efficacy of risk-reduction counseling to prevent human immunodeficiency virus and sexually transmitted diseases: a randomized controlled trial. JAMA. 1998;280(13):1161-1167.

31. Bolu OO, Lindsey C, Kamb ML, et al; Project RESPECT Study Group. Is HIV/sexually transmitted disease prevention counseling effective among vulnerable populations? a subset analysis of data collected for a randomized controlled trial evaluating counseling efficacy (Project RESPECT). Sex Transm Dis. 2004;31(8):469-474.
Open Access Journal of Contraception

\section{Publish your work in this journal}

Open Access Journal of Contraception is an international, peerreviewed, open access, online journal, publishing original research, reports, reviews and commentaries on all areas of contraception. In addition to clinical research, demographics and health-related aspects, the journal welcomes new findings in animal and preclinical studies

\section{Dovepress}

relating to understanding the biological mechanisms and practical development of new contraceptive agents. The manuscript management system is completely online and includes a very quick and fair peer-review system. Visit http://www.dovepress.com/testimonials.php to read real quotes from published authors. 